\title{
Textile Materials in Medicine - Some Insights on Current Trends
}

\author{
N Gokarneshan* \\ Department of Textile technology, Park college of engineering and technology, India
}

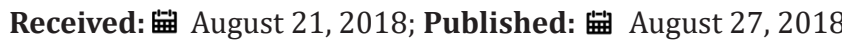

*Corresponding author: N Gokarneshan, Formerly professor and head, Department of Textile technology, Park college of engineering and technology, Coimbatore, Tamil Nadu, India

\begin{abstract}
The article highlights some significant trends in use of textile materials in medicine. The kinetics of swelling and drug release of composite wound dressing material in various $\mathrm{pH}$ buffer solutions has been studied by simulating the $\mathrm{pH}$ range of wounds. Composite dressing material is prepared by grafting polyacrylic acid-co-acrylamide hydrogel on the cotton fabric using polyethylene glycol as cross-linking agent. Natural dyes have been extracted from camphor plant (Cinnamomum camphora) dry leaves in alkaline medium and are then applied onto silk fabric by exhaust dyeing process. Properties such as ultraviolet protection, antimicrobial property, colour strength values, and colour fastness of the silk dyed using plant extract have been investigated.
\end{abstract}

Keywords: Antibacterial property; UV protection; Silk fabric; Composite dressing; Cotton fabric; Swelling degree

\section{Introduction}

Over the past few decades, a number of research groups have been working on strategies to promote the wound healing process and the development of wound dressing materials. An ideal wound dressing should meet the following criteria such as debridement, retention of moist wound environment, low adherence, prevention of infection and absorption of blood and exudates, etc. Different types of materials, such as hydrogel, hydrocolloid, alginate and silicone gel have been used to produce the modern dressings [1,2]. The dyes/colorants obtained from natural sources like plants, animals and minerals are termed as natural dyes [3]. Synthetic dyes are more toxic, non-biodegradable, allergic, and not environmentally friendly as compared to natural dyes [4]. Natural dyes are consumed 10,000 tone's per year which is equal to $1 \%$ of the total world synthetic dyes consumption $[5,6]$. Petrochemical source is the origin of synthetic dyes and some of these dyes contain harmful carcinogenic amines [7]. Germany has banned the production of azo dyes because of their severe harmful effects on living organisms [8]. Natural dyes of some plants not only dye with unique and elegant colours, but can impart antibacterial, deodourising and ultraviolet protective properties to fabrics [9].

\section{Mechanism of Swelling and Drug Release of Composite Wound Dressin}

Hydrogels possess most of the desirable characteristics of an ideal dressing, such as moist healing, non-adherence and absorption of excess exudate. They also facilitate the autolysis of necrotic tissue and do not support bacterial growth $[3,10]$. Highly porous structure and aqueous swelling of hydrogel permit the loading of the drug into the gel matrix and subsequent release at the desired site. All pH sensitive polymers contain pendent acidic or basic groups that either accept or donate protons in response to the environmental $\mathrm{pH}$. The water content of hydrogels at equilibrium swelling condition is one of the basic properties that make them useful in drug delivery at wound site. The network porosity of these hydrogels changes with electrostatic repulsion. Swelling of a hydrogel increases as the external $\mathrm{pH}$ increases in the case of weakly acidic (anionic) groups but decreases if the polymer contains weakly basic (cationic) groups. Hydrogels based on poly (AAm) and poly (AAc) have the capacity to absorb a substantial amount of water, so these hydrogels may be considred a potential candidate for drug delivery systems at wound site [4-6,11-13]. Many formulations have been developed for various drug release using MEPBA, ascorbic acid, Gentamicin sulphate, Theophylline, BSA, as therapeutic agents [7-10,14-17] (Figure 1).

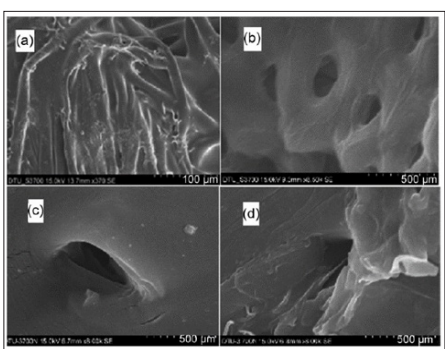

Figure 1: SEM images of composite wound dressing (a) before swelling, and (b), (c), and (d) after swelling at $\mathrm{pH}$ $5.5,7.0$ and 8.5 respectively [29]. 
Solute diffusion, polymeric matrix swelling, and material degradation are the main driving forces for solute transport from drug containing polymeric matrices. When a drug is incorporated into a swellable polymer, diffusivity of encapsulated molecules of drug is strongly affected by the degree of swelling and crosslinking density of the gel [11-18]. Many mathematical models such as Peppa's model, Higuchi model, first order kinetics and second order kinetics model have been developed to interpret the swelling and drug release profile of a polymer network. The quantitative interpretation of the results obtained in swelling or drug release assays is easier using these mathematical models which describe the swelling or release or profile as a function of kinetic parameters [12-19]. The most widely used kinetic model for swelling and drug release profile is Korsermeyer- Peppa's model. This model is generally used to analyses the release of drug, when the release mechanism is not well known or when more than one type of release phenomena could be involved [13-20].

Korsermeyer- Peppa's model uses semi-empirical equation to analyze the kinetic data of the drug released at initial stages (approximately 60\% release) [14-21]. To use this equation, it is also considered that release occurs in one dimensional way and that the system width-thickness or length-thickness relation should be at least 10 . To obtain a better model beyond $60 \%$, models other than Peppa's model should be considered. Zero order kinetic model shows that the hydrogels do not aggregate and release drug slowly. Hydrogels, which contain water soluble drug in porous matrices, release the drug in a way that is proportional to the amount of drug remaining in the dressing material, it is shown by first order kinetics. If the drug particles dispersed in a uniform matrix behave as a dispersing media, it can be best described by Higuchi model $[13,20]$. Swelling can also be described by second order kinetic model $[15,16,22,23]$. This equation indicates that the swelling rate is a function of the treatment time. So, mathematical modelling, whose development requires the comprehension of all the phenomena affecting drug release kinetics, has a great importance in the process optimization of controlled release formulation. Hydrogels can be used as medicated dressing to incorporate drug or antibiotics which have therapeutic value. But their application as medicated dressing is hindered by its low mechanical strength which can be improved by using hydrogels as composites, hybrids or copolymers. Radical precipitation copolymerization, RAFT controlled synthesis and composite dressings (where hydrogel is coated on the fabric material) have also been used to improve its low mechanical strength [17-19,24-26]. A composite wound dressing has been synthesized by grafting hydrogel layer on the cotton fabric for drug release application. Composite dressing showed good tensile strength in wet conditions and drug release at different $\mathrm{pH}$.

Protein nano carriers such as gelatin, collagen, albumin, and zein are used as drug delivery devices due to their exceptional characteristics such as biodegradability, no antigenicity, high nutritional value, abundant renewable sources and extraordinary binding capacity for various drugs. Over the past few decades, albumin has emerged as a versatile macromolecular carrier for therapeutic and diagnostic agents. Albumin has been shown to be nontoxic, non-immunogenic, biocompatible, biodegradable, and metabolizable into nontoxic degradation end products. Hence Bovine serum albumin has been used as a model drug in the experiment $[20,21,27,28]$. Kinetics of swelling and drug release have been studied for different hydrogels. In case of composite dressing, no study has been reported on kinetics of swelling and drug release. In view of above, study has been aimed at evaluating the swelling and drug release kinetics, so as to ascertain the mechanism involved in drug release from composite wound dressing. The wound dressing is prepared by grafting poly (acrylic acid-co-acrylamide) hydrogel onto cotton fabric using PEG as crosslinker and BSA as a model drug.

Cotton fabric is grafted with polyacrylic acid-co-acrylamide hydrogel, cross linked with polyethylene glycol to prepare the composite dressing material. Composite dressing is loaded with drug BSA. The swelling and drug release tests are conducted on these materials. Based on the experimental results a number of findings have been deduced. Results show maximum equilibrium swelling at $\mathrm{pH} 7$ which causes maximum drug release [29]. At $\mathrm{pH}$ 5.5 and 8.5, the swelling is less, leading to slow drug release in these $\mathrm{pH}$ solutions. It is also shown that swelling kinetics at $\mathrm{pH} 5.5$ and 7 solutions follows first order kinetics model while that at $\mathrm{pH}$ 8.5 follows second order kinetics model. So, the swelling process, for long time period, is not governed by the diffusion but by the relaxation of the polymer chains. All these factors contribute in the controlled drug release, as it is directly influenced by swelling and pore size. Drug release kinetics follows Peppas model and value of release exponent is less than 0.5 at all $\mathrm{pH}$, so drug release follows diffusion control mechanism. This system is modulated release system which shows $\mathrm{pH}$ dependent swelling behavior and it is also a matrix system which shows diffusion-controlled drug release. So, these new wound dressing materials have a great potential as delivery hosts for wound healing process in the pharmaceutical field.

\section{Silk Fabric Dyed with Natural Dye For UV and Bacterial Protection}

Camphor can be extracted from the wood of camphor laurel (Cinnamon camphora) and other plants belonging to laurel family. It is a white crystalline substance possessing pungent taste and strong odor. Camphor tree is native to china, India, Mongolia, japan, Taiwan and a specie of this class is also grown in southern part of united states [30]. Camphor is a magic plant having many applications in pharmaceutical field, for example natural decongestant, cough suppressant, topical analgesic, antiseptic, antispasmodic, antipruritic, anti-infective, anti-inflammatory, rubefacient, contraceptive, mild expectorant, etc [31]. The camphor is the main component found in leaves of cinnamon camphora and minute quantities of cineol, linalool, eugenol, limonene, safrole, $\alpha$-pinene, $\beta$-pinene, $\beta$-myrcene, $\alpha$ - humulene, p-cymene, nerolidol, borneol, and camphene are also obtained [32].

A white crystalline ketone is known as camphor found commonly in all parts of the cinnamomum camphora tree. Traditionally, 
camphor has been used for the treatment of chest congestion and inflammatory diseases, like rheumatism, sprains, bronchitis, asthma and muscle pain [33]. Camphor is used for activation of some of TRP (transient receptor potential) producing warm sensation, the sensory nerves are excited and desensitized, relieving the pain, itch and irritation in applied area. In radiotherapy, camphor can be used as potential sensitizing agent [34]. A drug based on camphor is used for the treatment of some breast and prostate cancer patients [35]. A herbal preparation based on camphor is effective in treatment of chronic inflamatory diseases. Atrazine, a commonly used herbicides causes DNA damage and biochemical changes in mice which can be encountered by using cinnamon camphora, namely, cinnamon and camphorin have shown their inhibitory effect against cultured carcinoma cells [36,37]. Camphor containing plants are expected to play a vital role in nutraceutical and pharmaceutical applications in future $[38,39]$.

The major environmental cause for skin damage is due to its exposure to ultraviolet radiation. Ultraviolet B radiations are more harmful as compared to ultraviolet A radiations. Long term ultraviolet B exposure to human skin creates wrinkles, and an increased risk of epithelial skin cancer [40]. Ultraviolet protection factor is the protection provided by a material against ultraviolet radiation [41]. Ultraviolet radiations can be blocked by using adequate clothing materials and the level of protection offered by them depends on various factors such as fiber chemistry and physics, yarn properties, fabric construction, weight, thickness and cover factor, its colour and finishing treatments [42]. Beside UV protection many natural dyes obtained from various plants are known to have antimicrobial properties [43-45]. Studies have been carried out on ultraviolet protection and antimicrobial properties of silk fabric dyed with camphor plant leaf extract. Application of dye extract on silk fabric shows excellent ultraviolet protection factor, UVA and UVB blocking.

Camphor plant extract gives excellent results in UV protection properties due to the presence of camphor, cineol, linalool, eugenol, limonene, safrole, $\alpha$-pinene, $\beta$-myrecene, $\alpha$-humulene, $\mathrm{p}$-cymene, nerolidol, borneol, and camphene in its leaves [46]. The extract imparts excellent antibacterial activity, against all three test organisms used, namely, E.Coli, S.Aureus, and C.Albican. Colour strength values and overall colorfastness values are found very good. It is concluded from the results that utilizing extracted natural colourants as dyeing materials significantly facilitates production of quality textiles having good dyeability, ultraviolet protection and antibacterial properties.

\section{Conclusion}

Investigations on the swelling and drug release kinetics of composite wound dressing material in various $\mathrm{pH}$ buffer solutions reveal maximum equilibrium swelling at $\mathrm{pH}$ 7.0. Swelling kinetics at pH 5.5 and pH 7.0 solutions follow first order kinetics model, while that at $\mathrm{pH} 8.5$ solution follow second order kinetics model. The drug release kinetics of composite dressing is investigated at different $\mathrm{pH}$ using model drug Bovine serum albumin. Drug release kinetics follows Peppa's model and drug is released by Fickian diffusion mechanism. The surface morphology of the composite dressing is analyzed by scanning electron microscopy. The pores of different sizes are observed at different $\mathrm{pH}$. The drug release from composite dressing is directly is directly influenced by swelling and pore size.

These composite wound dressing materials have a great potential to be used as a medicated dressing in wound healing process for non-chronic wounds. Studies on the application of natural dyes extracted from camphor plant, on silk fabric by means of exhaust dyeing process reveal excellent UV protection properties and are very effective in blocking UVA and UVB radiations. The fabric dyed with natural extract shows antimicrobial properties, which is proved by bacterial reduction in quantitative tests. The colour fastness to washing and rubbing is found very good to excellent and colour fastness to light is poor. Silk fabric dyed for less time shows golden colour, while the increased dyeing time shows reddish brown colour. The UV protection and antimicrobial performance of camphor plant leaf extract are found excellent.

\section{References}

1. Boateng JS, Mathews KS, Stevens HN, Eccleston GM (2008) Journal of pharmaceutical science,

2. $97(8): 2892$.

3. Daunton C, Kothari S, Smith L, Steele D (2012) Wound practice and research, 20(4): 174

4. Samanta AK, Konar A (2011) Dyeing of textiles with natural dyes (INTECH open access publisher).

5. Prabhu K, Bhule AS (2012) Journal of natural products and plant resources pp. 2-649.

6. Punrattanasin $\mathrm{N}$, Nakpathom $\mathrm{M}$, Somboon B, Narumol $\mathrm{N}$, Rungruangkitkrai N, Mongkholrattanasit R, (2013) Indian crops production pp. 49-122.

7. Monghkolrattanasit R, Krystafek J, Weiner J (2010) Fibers and polymers pp. 11-346.

8. Hunger K (2003) Industrial dyes, chemistry, properties, Applications, John Wiley and sons.

9. Almahy H, AM, Band Ali A (2013) Research journal of chemical sciences p. 3-63.

10. Monghkolrattanasit R, Krystafek J, Weiner J, Vikova M (2011) Fibres and Textiles in eastern Europe, p. 19-94.

11. Bajpai AK, Shukla SK, Bhanu S, Kankane S (2008) Progress in polymer science. pp. 33-1088.

12. Adnadjevic B, Jovanovic J (2009) Colloid surface B. p. 69-31.

13. Ruvalcaba AM, Sanchez Diaz JC, Becerra F, Cruz-Barba LE, GonzalezAlvarez A (2009) eXPRESS polymer letters 3(1): 25.

14. Thakur A, Wanchoo RK, Singh P (2011) Chemical and Biochemical engineering 25(4): 471.

15. Katime A, Novoa R, Diaz De Apodaca E, Mendiza Bal E, Puig J (1999) Polymer Testing, pp. 18-559.

16. Serra L, Domenech J, Peppas NA (2006) Biomaterials 27(31): 5440.

17. Povea M, Monal W, Rodriguez JC, Pat A, Rivero N, Covas C (2011) Material science and applications,

18. pp.2509.

19. Purwar R, Rajput P, Srivastava CM (2014) Fibers and Polymers 15(7): 1422. 
20. Peppas NA, Khare AR (1993) Advances in drug delivery review p. 1-11.

21. Fu Y, Kao WJ (2010) Expert opinions on drug delivery 7(4): 429.

22. Costa P, Lobo JMS (2001) European journal of pharmaceutical science pp. 13-123.

23. Korsermeyer RW, Peppas NA (1983) Control release delivery systems p. 77.

24. Ganji F, Farahani SV, Farahani EV (2010) Iran polymer journal pp. 19375.

25. Pourjavadi A, Mahdavinia GR (2006) Turkey journal of chemistry pp. 30-595.

26. Yue Y, Sheng X, Wang P (2009) European polymer journal pp. 145-309.

27. Liu J, Cui L, Kong N, Barrow CJ, Yang W (2014) European polymer journal p. 9-50.

28. Gupta B, Agarwal R, Alam MS (2010) Indian journal of fibres and textile research pp.35-174.

29. Huang S, Fu X (2010) Journal of control release pp.142-149.

30. Elzhogby AO, Samy WM, Elgindy NA (2012) Journal of control release pp.161-38.

31. Agrawal A, Purwar R (2018) Indian journal of fibre and textile research pp. 43-104.

32. Frizzo CD, Santos AC, Paroul N, Serafini LA, Dellacassa E, Lorenzo D, Moyna P (2003) Brazilian Archeology, Biology and Technology pp. 43313.

33. Ho CL, Wang EIC, Su YC (2009) Forestry research quarterly pp. 3177.

34. Pickrell KD, Miller-Keane (2003) Encyclopedia and dictionary of medicine, nursing and allied health. p. 77-70.

\section{ISSN: 2574-1241}

DOI: $10.26717 / B J S T R .2018 .08 .001650$

N Gokarneshan. Biomed J Sci \& Tech Res

(C) This work is licensed under Creative

Submission Link: https://biomedres.us/submit-manuscript.php
35. Salman AS, Farghaly AA, Donya SM, Shata F Journal of American Science pp. 8-190.

36. Ghanta V, Hiramoto N, Solvason H, Soong S, Hiramoto R (1990) Cancer research pp. 45-50.

37. Weiss L, Barak V, Raz I, Or R, Slavin S, Ginsburg I (2010) Alternative medicine studies p. 1-1.

38. Ling J Liu WY (1996) Cell Biochemical function pp. 14-157.

39. Liu R, Wei G, Yang Q He W, Liu W (2002) Biochemical society pp. 362659.

40. Edris AE (2007) A review phytother research pp. 21-308.

41. Kumar M, Ando Y (2003) Diamond related materials pp. 12-1845.

42. (2007) Feng S, Zhang L, Chen J, Zhang J, Journal of clean production pp. 15-266.

43. (1996) Sun protective clothing - Evaluation and classification AS/NZ 4339 (Australian Standards/New Zealand standards).

44. Saravanan D (2007) Autex research journal p. 7-53.

45. Reinert G, Fuso F, Hilfiker R, Schemidt E (1997) AATCC review p. 29-36.

46. Rajendran R (2011) Journal of textile, apparel, technology and management p. 1-7.

47. (2005) Han S, Yang Y, Dyes and pigments pp. 64-157.

48. Jiang H, Khan A, Yao J, Hussain MT (2018) Indian journal of fibres and textile research pp. 43-242.

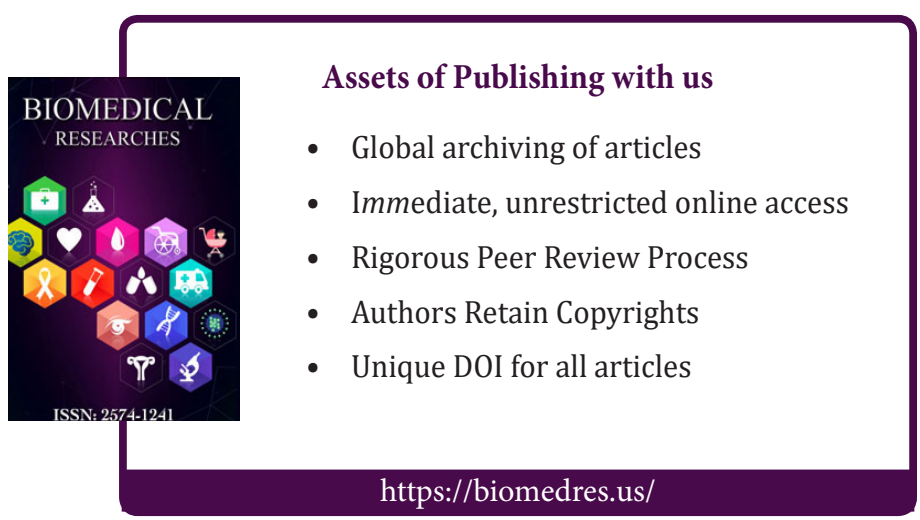

Cite this article: N Gokarneshan. Textile Materials in Medicine - Some Insights on Current Trends. Biomed Sci\&Tech Res 8(3)- 2018. 